\title{
Apontamentos retórico-musicais no Largo do Concerto n.5, BWV 1056, de Johann Sebastian Bach
}

\author{
Pablo Alberto Lanzoni (UFRGS, Porto Alegre, RS) \\ pablolanzoni@ibest.com.br
}

\begin{abstract}
Resumo: 0 presente artigo discute a análise retórica do Largo do Concerto n.5 em Fá menor, BWV 1056 de Johann Sebastian Bach. No primeiro momento, é apresentada uma revisão dos princípios retóricos e de como eles se transportam à música. A seguir, é proposta uma análise do movimento mencionado, partindo da discussão já exposta. 0 exercício analítico exemplifica como os princípios retóricos estão intimamente relacionados à música do período barroco.
\end{abstract}

Palavras-chave: retórica em música; análise musical; J. S. Bach; BWV 1056.

\section{Musical-rethorical notes on J. S. Bach's Largo from Concerto n.5, BWV 1056}

\begin{abstract}
The present article is based upon the rhetorical analysis from Johann Sebastian Bach's Largo of Concert n. $5 \mathrm{~F}$ minor, BWV 1056. First, a review of the rhetorical principles and how they convey themselves to the music is introduced. Next, it is presented an analysis of the mentioned movement from the discussion already exposed. The analytical exercise exemplifies how the rhetorical principles are related to the Baroque period music.
\end{abstract}

Keywords: rhetoric in music; music analysis; J.S. Bach; BWV 1056.

\section{1 - Introdução}

A teoria retórico-musical, cujos postulados foram registrados em uma série de tratados, através do nome latino genérico musica poetica, parte de uma aspiração proveniente do Renascimento, de imitar modelos e técnicas da cultura clássica. Completa este desejo o anseio de teóricos e compositores em constituir, na música, uma força telúrica, capaz de mover e sacudir os afetos da plateia, assim como os bons oradores ao proferirem seus discursos. Deste modo, extrair da retórica as ferramentas necessárias para suscitar tais efeitos transformou-se em tarefa fundamental para os músicos barrocos. A edificação de uma complexa teorização retórica da música foi sua consequência.

Este artigo pretende discutir o Largo, segundo movimento do Concerto n.5, BWV 1056, de Johann Sebastian Bach em sua estrutura retórico-musical. Considerando as particularidades da Inventio, da Dispositio e da Elocutio, busca-se identificar os aspectos formais e discursivos da obra, revelando algumas das figuras retórico-musicais presentes em cada uma de suas partes.

\section{2 - Apontamentos retóricos}

A aproximação entre música e retórica remete à antiguidade clássica. Musica e Rhetorica pertenciam ao sistema das septem artes liberales, uma organização de ensino que perpassou os séculos, impondo-se como portadora dos saberes fundamentais do ocidente. As septem artes liberales dividiam-se em Quadrivium, constituído por Musica, Arithmetica, Geometria e Astronomia, e Trivium, ao qual pertenciam Rhetorica, Grammatica e Dialectica. Segundo ASSUMPÇÃO (2007, p.114): 
Pelas septem artes liberales, música e retórica atravessaram toda a época medieval [...], adentrando o universo renascentista e barroco. Com a lenta emancipação da música da palavra no século XVIII, a autonomia da música instrumental exigiu que formas musicais especificas se erigissem, para abarcar o material musical em franco desenvolvimento.

As origens da retórica remetem à Grécia do século $V$ a.C. A sistematização dos procedimentos que idealizaram e construiram os diferentes tipos de discurso provém da região da Sicilia, de onde foi levada a Atenas e Roma. A retórica foi descrita como um dos saberes fundamentais constituintes do Trivium, o qual, durante séculos, norteou a formação da aristocracia ocidental. Para MERSIOVSKY (2005), o Trivium (triplex via ad eloquentiam, arte discendis) é o resultado da união entre música e retórica e coordenou a prática musical em diferentes períodos. BERISTÁIN (1995, p.421) afirma que:

o ensino da retórica procurava um fundamento moral ao aluno já que, para dominar a arte de falar bem se requer pensar bem, e para pensar bem é necessário viver bem, sem isto, não é possivel nem comover, nem convencer: assim não é possível persuadir.

De Platão provêm algumas das inquietações acerca da retórica que chegaram aos dias atuais. Platão sugere que a retórica é, até certo ponto, diferente da noção de 'verdade', isto é, o que pertence ao mundo real não necessariamente pertence ao mundo das ideias. Ele defendia a tese de que o ensino da retórica não poderia ocorrer, pois esta se relaciona intimamente a uma virtude pessoal e não pertence àqueles desprovidos desta virtuosidade. (LEACH, 2008) Em Roma, impulsionados pelo interesse no discurso persuasivo e no ensino da retórica, solidificaram-se alguns manuais retóricos que descrevem e interpretam figuras de linguagem, padrões gramaticais e dimensões estéticas que tornam textos e falas atrativos.

Durante a Idade Média, música e texto estiveram indissoluvelmente ligados para servir aos princípios da contemplação e da adoração religiosa. Para ASSUMPÇÃO (2007), De institutione musica de Boécio, obra que concentra várias teorias musicais da antiguidade e um dos principais textos usados nos estudos de música durante a Idade Média, é um marco no desenvolvimento da teoria musical e influente no estreitamento das relações entre música e retórica.

Nos séculos XVI, XVII e XVIII, a ação da retórica na cultura, na educação, na religião, nas artes e na sociedade foi intensa. No Renascimento, com o Humanismo e o Protestantismo, por vias diferentes, música e retórica passaram a ser acompanhadas uma da outra. Em relação à música, CANO (2000) diz que o corpus teórico da retórica musical, no Barroco, é produto dos tratados produzidos entre 1535 e 1792. Estes foram denominados por seus autores como musica poetica ${ }^{1}$, em alusão à poética literária, neles se faz referência à íntima relação entre música e retórica; ao papel do músico como orador, cuja tarefa principal é persuadir o público; à origem e ao funcionamento dos afetos; ao sistema retórico musical. CANO (2000) afirma ser possivel, através destes tratados, demonstrar a importância da retórica nos processos compositivos da época, propiciando uma aproximação melhor documentada aos pressupostos históricos, culturais, científicos, epistemológicos que permearam a atividade musical do Renascimento tardio e do Barroco.

\section{3 - A questão dos afetos}

Muitas das particularidades associadas à música barroca foram influenciadas pelo anseio de recuperar princípios da tragédia clássica grega. Ao final do século XVI, um grupo de poetas, músicos e nobres, dentre eles Vincenzo Galilei, Giulio Caccini e Ottavio Rinuccini, reuniam-se na casa do Conde Giovanni de Bardi em Florença, com o intuito de discutir assuntos relacionados às artes e, em especial, à tentativa de expressar fortes emoções através da subordinação da música à poesia.

Dos encontros da Camerata Florentina, denominação dada ao grupo, construiu-se um estilo musical que elegeu o discurso como protagonista em música. 0 ritmo deveria ser o ritmo da fala, e todos os elementos musicais deveriam contribuir para a descrição do afeto representado pelo texto. Para SADIE (1994, p.9), a doutrina dos afetos é:

o termo utilizado para descrever um conceito teórico da era barroca, derivado das ideias clássicas de retórica, sustentando que a música influenciava os "afetos" (ou emoções) do ouvinte, segundo um conjunto de regras que relacionavam determinados recursos musicais (ritmos, motivos, intervalos etc.) a estados emocionais especificos.

A sistematização da doutrina dos afetos teve grande influência no desenvolvimento da música barroca. A vinculação da música a estados emocionais afetivos alcançou no período barroco uma complexa teorização. MATTOS (2009, p.37) afirma que:

A Teoria dos Afetos (Affektenlehre), desenvolvida durante o periodo Barroco, tem como princípio fundamental o conceito de que cada peça musical, ou movimento de uma obra mais ampla, deve representar somente um estado de alma, afeto ou emoção. Esta é uma diferença considerável com relação às teorias de representação musical dos madrigalistas, pois, para estes a 'imitação' de emoções ou situações era considerada em um sentido local, ou seja, através da representação de cada palavra ou verso da poesia. Por seu turno, a Teoria dos Afetos preconiza que a música deve expressar o pathos ${ }^{2}$ geral da poesia e não descrever cada um de seus momentos específicos.

Embora a 'teoria dos afetos' não seja aproximada à música de Johann Sebastian Bach com frequência e não sendo esta a pretensão deste artigo, da discussão exposta infere-se a forte inclinação dos músicos dos primeiros anos do século XVI em eleger, no sentido do texto, o protagonista da relação música e palavra, característica que se desdobrou por todo o Barroco. A preocupação discursiva que perpassou a era barroca não ecoou apenas na música vocal, alcançando a música instrumental que se encontrava em sistematização no período. 


\section{4 - 0 Largo do Concerto n.5 em Fá menor, BWV 1056, de Johann Sebastian Bach e sua estrutura retórico-musical}

Datado de 1742, o Concerto n.5 em Fá menor, BWV 1056, de Johann Sebastian Bach está organizado em três movimentos: Allegro Moderato, Largo, Presto. Ele pertence à última década da vida do compositor, quando, segundo SADIE (1994, p.61), o "artifício contrapontístico" predominou em sua obra. A estrutura do concerto, recorrente em outras produções do gênero, denomina-se 'forma italiana', pois se constitui de dois movimentos rápidos (Allegro e Presto) e de um intermediário lento (Largo).

O BWV 1056 foi concebido para cravo, dois violinos, viola e contínuo e pertence a uma série de concertos - BWV 10521059 - constituídos por esta instrumentação. 0 movimento intermediário, Largo, é basicamente uma transcrição da Sinfonia ${ }^{3}$ oriunda da Cantata BWV 156, Ich steh mit einem Fuß im Grabe (Eu estou com um pé no túmulo) de 1729, composta para dois violinos, viola, contínuo e oboé.

0 procedimento de submergir, em uma obra, os fragmentos de outras obras, tal como sucede no BWV 1056, é recorrente na produção musical de Bach. Grandes demandas exercidas pelos serviços religiosos para os quais dedicou seu trabalho, aliadas a sua prática musical e ao oficio de professor que muitas vezes desempenhou, poderiam ser considerados se esta questão fosse pormenorizada.

Ao mencionar a cantata BWV 156, Ich steh mit einem Fuß im Grabe, deve-se frisar que um coral ou uma cantata de Bach são permeados de elementos simbólicos. Segundo MASSIN (1997, p.464):

\begin{abstract}
quando põe algum texto em música - e trata-se quase sempre de um texto religioso -, Bach jamais deixa passar uma ideia uma imagem ou uma palavra importante, sem dela oferecer musicalmente uma transcrição simbólica. Bach possui todo um arsenal de procedimentos de escrita musical (melódicos ou harmônicos) que Ihe permitem, a qualquer momento, modificar a marcha do desenrolar da música, mudar-lhe a direção e traduzir, assim, a imagem contida no texto que transcreve musicalmente.
\end{abstract}

A explicitação de ideias, imagens ou palavras, através de elementos simbólicos, é procedimento sistemático na obra de Bach, e parece ser mais evidente na música vocal que na música instrumental. 0 texto em Bach é fator determinante. No entanto, a tarefa de buscar simbolismos em sua música instrumental é viável. BODKY (1980, p.241) afirma4:

já que a chave para o entendimento da música vocal de Bach quase sempre reside na compreensão do significado dos elementos 'pictóricos', não é injustificável pesquisar mecanismos semelhantes em sua música para teclado.

Inventio, Dispositio, Elocutio, Memoria e Pronuntiatio são os constituintes com os quais é possivel discutir o sistema retórico. Segundo RODRIGUÊS (2001), todos, com exceção da Memoria, foram aplicados à música. Memoria é a única parte do sistema retórico que não foi sequer mencionada nos tratados musicais do Barroco. Para LEACH (2008), é notável que estas categorias existam há mais de dois mil anos, antes como métodos com os quais se devia exercitar o discurso e depois, por Aristóteles, como um modo de examinar a estrutura de discursos particulares.

A produção teórica da qual se apropriaram os elementos retóricos aplicados à música, no período barroco, é fundamentalmente germânica. Embora princípios retóricos tenham influenciado a composição musical na Itália, França e Inglaterra, foi na Alemanha que seu desenvolvimento culminou na adoção e na adaptação de métodos, terminologia e estruturas retóricas remetidas à música. Dentre os principiais tratadistas retórico-musicais do período barroco citam-se Burmeister (1564-1629), Kircher (1601-1680), Printz (1641-1717), Vogt (16691730), Walther (1684-1748), Mattheson (1681-1764), Scheibe (1708-1761) e Forkel (1749-1818).

A discussão analítica que segue examina o Largo do Concerto n.5 em Fá menor, BWV 1056, de Johann Sebastian Bach, através do entendimento da Inventio e da Dispositio. No decorrer do exercício, serão convocadas algumas das figuras retórico-musicais presentes nas estruturas descritas e pertencentes à Elocutio. A Pronuntiatio não será considerada para esta análise.

\section{1 - Análise da estrutura retórico-musical}

Ciente das aproximações entre o Largo do Concerto n.5 em Fá menor, BWV 1056, e a Sinfonia, movimento inicial da Cantata BWV 156, torna-se oportuno discutir, através de paralelos entre ambas as obras, os elementos pertencentes ao domínio da Inventio.

Inventio é a obtenção de argumentos, ideias e informações estratégicas a serem empregados no discurso. Para ASSUMPÇÃO (2007), em música, Inventio é a determinação das ideias centrais (melodias, temas), da tonalidade, do andamento, dos metros, dos timbres, ou seja, das decisões composicionais precedentes ao grafismo na partitura.

Fá menor é a tonalidade estrutural do Concerto n.5, BWV 1056. Segundo CANO (2000), teóricos barrocos apresentaram a tonalidade de Fá menor associada ao deprimido, por Charpentier (1670); ao desespero, por Mattheson (1713); ao lamento, por Rameau (1722). Fá maior - tonalidade que estrutura a Cantata BWV 156, Ich steh mit einem Fuß im Grabe - foi aliada à fúria e à cólera, por Charpentier (1670); à generosidade, à resignação e ao amor, por Mattheson (1713); ao tormento, por Rameau (1722).

0 Largo, movimento intermediário do BWV 1056, está em Lá bemol maior, tonalidade relativa à estruturante do concerto. A Sinfonia da Cantata BWV 156 está em Fá maior. Da transcrição efetuada por Bach, observa-se não apenas a reinstrumentação já referida, como também a transposição de tonalidades no reaparecimento do movimento em nova obra do compositor (Ex.1). 


\begin{tabular}{|c|c|c|c|}
\hline & $\begin{array}{c}\text { tonalidade } \\
\text { principal da obra }\end{array}$ & movimento em análise & $\begin{array}{c}\text { tonalidade do } \\
\text { movimento } \\
\text { discutido }\end{array}$ \\
\hline$B W$ 156 & Fá maior & Sinfonia & Fá maior \\
\hline BWV 1056 & Fá menor & Largo & Lá bemol maior \\
\hline
\end{tabular}

Ex.1 - Relações de tonalidades entre BWV 156 e BWV 1056 de Johann Sebastian Bach.

Os textos de Charpentier, Mattheson e Rameau, discutidos por CANO (2000), não apresentam descrições para a tonalidade de Lá bemol maior. SCHUBART (1806), teórico posterior a Bach, associa a tonalidade de Lá bemol maior ao eterno. 0 Largo do BWV 1056, relançado de nova obra, segundo a discussão do autor, se vincularia à prolongação da vida, à eternidade.

Embora pertençam a tonalidades diversas, tanto a Sinfonia quanto o Largo, encerram-se no mesmo acorde: Dó maior. A distância entre Lá bemol maior e Dó maior é mais ampla que entre Fá maior e Dó maior. No Largo, a fim de vencer tal percurso, a melodia desenhada por Bach percorre um compasso a mais para alcançar seu final. 0 acorde de Dó maior, que encerra ambos os movimentos, tanto na Sinfonia quanto no Largo, é de função dominante em suas tonalidades estruturantes, Fá maior e Fá menor. Assim, prepara o ouvinte para o movimento que segue e adquire função importante na estrutura e na íntima união das partes, tanto na Cantata quanto no Concerto. No Largo, o acorde Dó maior prepara o retorno à tonalidade principal da obra, confirmada no terceiro movimento: o Allegro em Fá menor.

CANO (2000) diz que, para Mattheson (1739), uma sinfonia expressa o afeto que rege a totalidade da obra a que pertence. Deste modo, a relação particular entre a Sinfonia da Cantata BWV 156 e o texto apresentado a partir dela ganha relevância.

A Cantata Ich steh mit einem Fuß im Grabe (Eu estou com um pé no túmulo), BWV 156, foi concebida para o terceiro domingo de Epifania do ano litúrgico. 0 texto apresentado remete ao leito de morte, de onde se espera a misericórdia e a compaixão de Deus, sobre Ele se depositando todas as esperanças de justiça, na eternidade. Tais intenções, vinculadas ao BWV 156 não desaparecerão no Largo do $B W V$ 1056. Elas são imanentes à obra, enraizadas à sua concepção e não podem ser desprezadas.

No que se refere à orquestração, Bach é idiomático: quando transcreve a linha melódica do oboé para 0 cravo, o compositor preenche a partitura com notas de passagem, bordaduras, appoggiaturas, grupetos, suspensões, antecipações, adornando a melodia, antes retilínea, com recursos característicos do instrumento utilizado para a máxima expressão de suas intenções.

A ordenação de argumentos e ideias estruturados na
Inventio, nos diferentes momentos do discurso, pertence à Dispositio. É possível ordenar a Dispositio em seis momentos: Exordium, Narratio, Propositio, Confutatio, Confirmatio, Peroratio. Segundo ASSUMPÇÃO (2007), a Dispositio equivale ao início do processo de grafia da partitura no processo composicional, ou seja, a suas linhas gerais e esboços fundamentais. Nesta análise, acompanha a discussão da Dispositio um mapeamento de elementos pertencentes à Elocutio, ou seja, a verbalização do discurso. Na Elocutio, os argumentos e ideias obtidos na Inventio e ordenados na Dispositio são transcritos, e se estabelecem as figuras retórico-musicais. Para o autor, as figuras retórico-musicais, classificadas como principais (fundamentais) e secundárias (superficiais), podem ser: desenhos melódicos; saltos melódicos específicos; emprego de dissonâncias (nota de passagem, preparação-suspensão-resolução); acordes específicos (quinta e sétima diminutas); procedimentos imitativos (cânone, fugatos, fugas); a própria tonalidade escolhida para o desenvolvimento da composição. Tudo para levar o ouvinte ao afeto desejado pelo compositor.

Exordium é a introdução ao discurso, a passagem do silêncio ao som. No Largo do Concerto n.5 em Fá menor, BWV 1056, é possível considerar a não existência do Exordium. 0 material temático apresentado pelo instrumento solista encontra-se no primeiro tempo do c.1 e é acompanhado pelos demais instrumentos (Ex.2). Não há introdução ou preparação, a melodia portadora do tema é lançada de imediato.

Narratio é a narração dos fatos, na qual se define o tema ou assunto principal. No Largo, a definição do tema surge entre os c.1-3 (Ex.2). 0 material temático apresentado pelo instrumento solista é composto basicamente de graus conjuntos e arpejos. Entre tais compassos, algumas figuras retórico-musicais já podem ser destacadas, como as anabasis - representação musical de sentido ascendente - entre a nota Dó do primeiro tempo do c. 1 e a nota Lá bemol do primeiro tempo do c.2, e as catabasis, de sentido descendente, entre a nota Lá bemol da segunda metade do primeiro tempo do c.2 e a nota Lá bemol do primeiro tempo do c.3.

As suspiratios, ou seja, os fragmentos melódicos interrompidos por pequenas pausas dispersas em seu discurso, remetem a suspiros (CANO, 2000), são 
recorrentes nos demais instrumentos que acompanham a melodia principal. Sempre em pizzicato, estas linhas constituem-se de pausas e colcheias, que se prolongam durante o movimento.

O emprego, no início de uma passagem musical, de intervalo harmônico imperfeito ou dissonante é denominado Inchoatio imperfecta. Esta figura retórico-musical é identificada no c.1, resultante da combinação entre a nota Lá bemol do contínuo com a nota Dó melódica. Ainda sobre a melodia do cravo, destacam-se as Periphrasis utilização de várias notas em pontos que somente uma seria necessária - no mordente do c.1 e no trinado do c.2. A harmonia utilizada no Ex.2 pode ser apresentada como: $\mathrm{Ab}$ : I V/3 IV/3 V7 I, encerrada através de cadência final.

Propositio é a fundamentação do discurso. No Largo, o trecho melódico que segue a Narratio mantém as mesmas características do material já exposto, no entanto o reforçando com tonicização à dominante (Ex.3). No c.3 há nova Inchoatio imperfecta. Entre os c.3-4 identifica-se um Saltus Duriusculus, ou seja, um salto intervalar de difícil execução para a voz cantada, seguido de anabasis e catabasis característicos do material temático. A Propositio é encerrada no c.7, no acorde de $\mathrm{Mi}$ bemol, de função dominante da tonalidade estruturante do Largo, criando assim uma tensão harmônica para continuidade do movimento e distanciando-se da atmosfera inicial.

A Confutatio refere-se à apresentação dos argumentos que confirmam a tese e a refutação dos que a contradizem. Em música, podem ser modulações e tonicizações, frequentemente acompanhadas por variações do material temático.

$\mathrm{Na}$ partitura em análise, as variações do material temático, encontradas entre os c.7-15 (Ex.4), acompanhadas de modulações e tonicizações, direcionam para a confirmação das seções já expostas. No terceiro tempo do compasso 7, o acorde de Lá diminuto indica a introdução de um gesto inesperado, uma dubitatio. A incerteza produzida no c.7 será resolvida no c.9, quando a nova atmosfera tonal é explicitada.

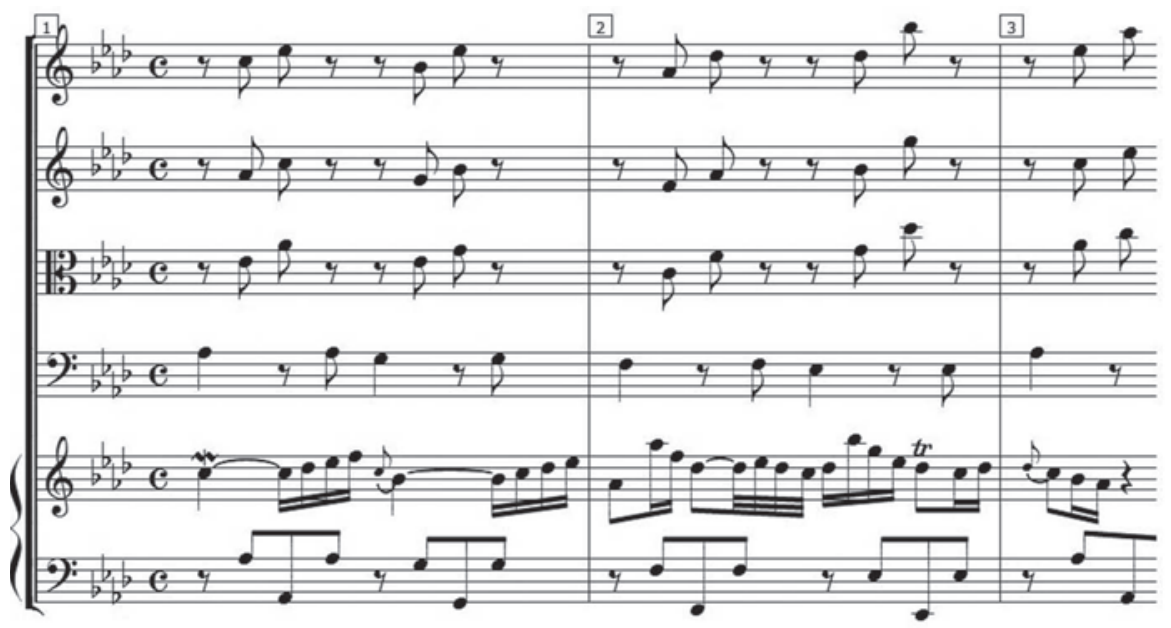

Ex.2 - Narratio (c.1-3) no Largo do Concerto n.5 em Fá menor, BWV 1056, de J. S. Bach.

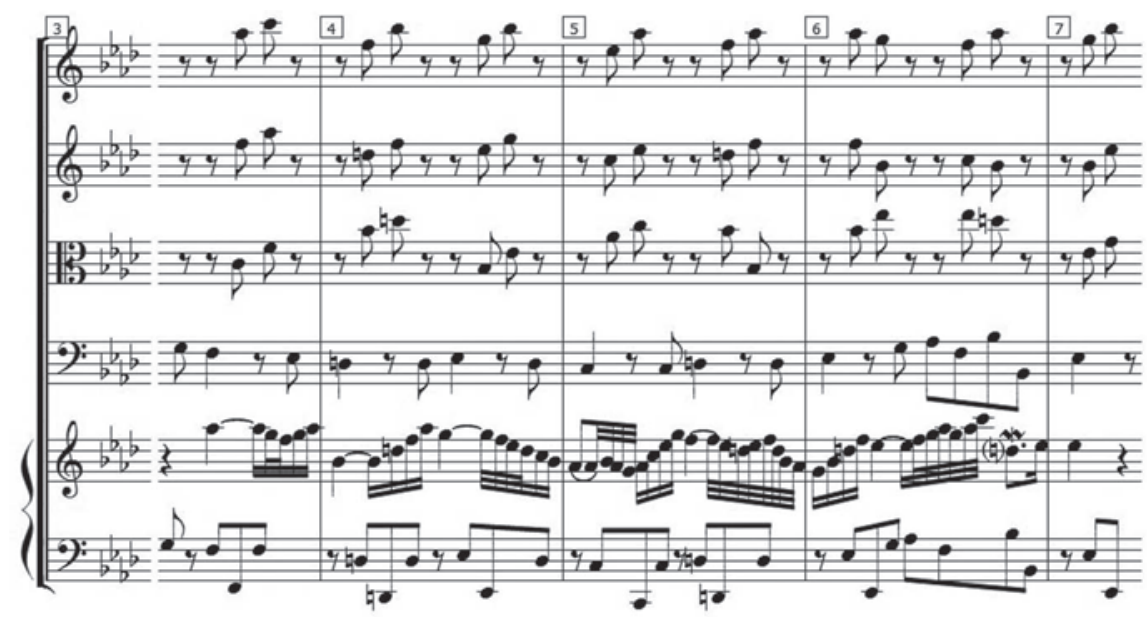

Ex.3 - Propositio (c.3-7) no Largo do Concerto n.5 em Fá menor, BWV 1056, de J. S. Bach. 
A nota Sol bemol, na linha melódica do c.8, pode ser entendida como uma heterolepsis - dissonância harmônica alcançada por grau conjunto ou salto - aqui uma sétima diminuta atingida por movimento de grau conjunto na melodia e salto no baixo -, assim como o intervalo gerado pelas notas Mi bemol melódica e Lá da voz inferior do cravo, no quarto tempo do c.8. Uma exclamatio, isto é, um salto melódico ascendente de sexta menor, é encontrada no terceiro tempo do c.9 da linha melódica entre as notas Fá e Ré bemol. No segundo tempo do c.10, entre Dó e Mi bemol, ocorre um saltus duriusculus. Esta nota Dó, alcançada através de salto, é acompanhada pela nota Sol bemol na voz inferior, resultando em uma heterolepsis.

A estrutura harmônica que começara com a sensação de incerteza lançada pelo acorde diminuto, resolve-se através de modulação para a tonalidade de Si bemol menor.

A passagem que encerra a Confutatio ocorre entre os c.11-15. A melodia, lançada através da nota Ré bemol, apresenta uma auxesis em relação ao material temático, isto é, uma transposição à segunda superior em uma mesma voz. No c.11 ocorre uma heterolepsis e uma inchoatio imperfecta, entre Ré bemol e Sol. Há saltus duriusculus entre os c.11-12, notas Si bemol e Ré bemol, e segundo tempo do c.14, entre as notas Si bemol e Dó. Na Confutatio, nota-se maior figuração em relação às seções anteriores e a apresentação de excertos do material melódico em métrica ternária, c.13-14.

No Largo, entre os c.15-19 (Ex.5), identificam-se o retorno e o reforço à ideia central, particularidade da Confirmatio. Após as modulações efetuadas na seção anterior, o c. 15 apresenta o regresso à tonalidade principal com a reexposição do material temático. A melodia reapresentada pelo instrumento solista é adornada por appoggiaturas, escapadas, trinados e notas de passagem, caracterizando as periphrasis, que permeiam as anabasis e as catabasis do material temático.

No c.15, entre as notas Dó da melodia e Lá bemol do contínuo há uma inchoatio imperfecta. Nesta seção, é possivel observar que a reapresentação da melodia e da harmonia a ela combinada, na qual estão inseridos alguns acordes, é ampliada frente à sua exposição. No entanto, mantém-se sua estrutura funcional: tônica - dominante - subdominante - dominante - tônica. No primeiro tempo do c.19 a Confirmatio é encerrada, demonstrando que a reafirmação da tonalidade principal foi conquistada.
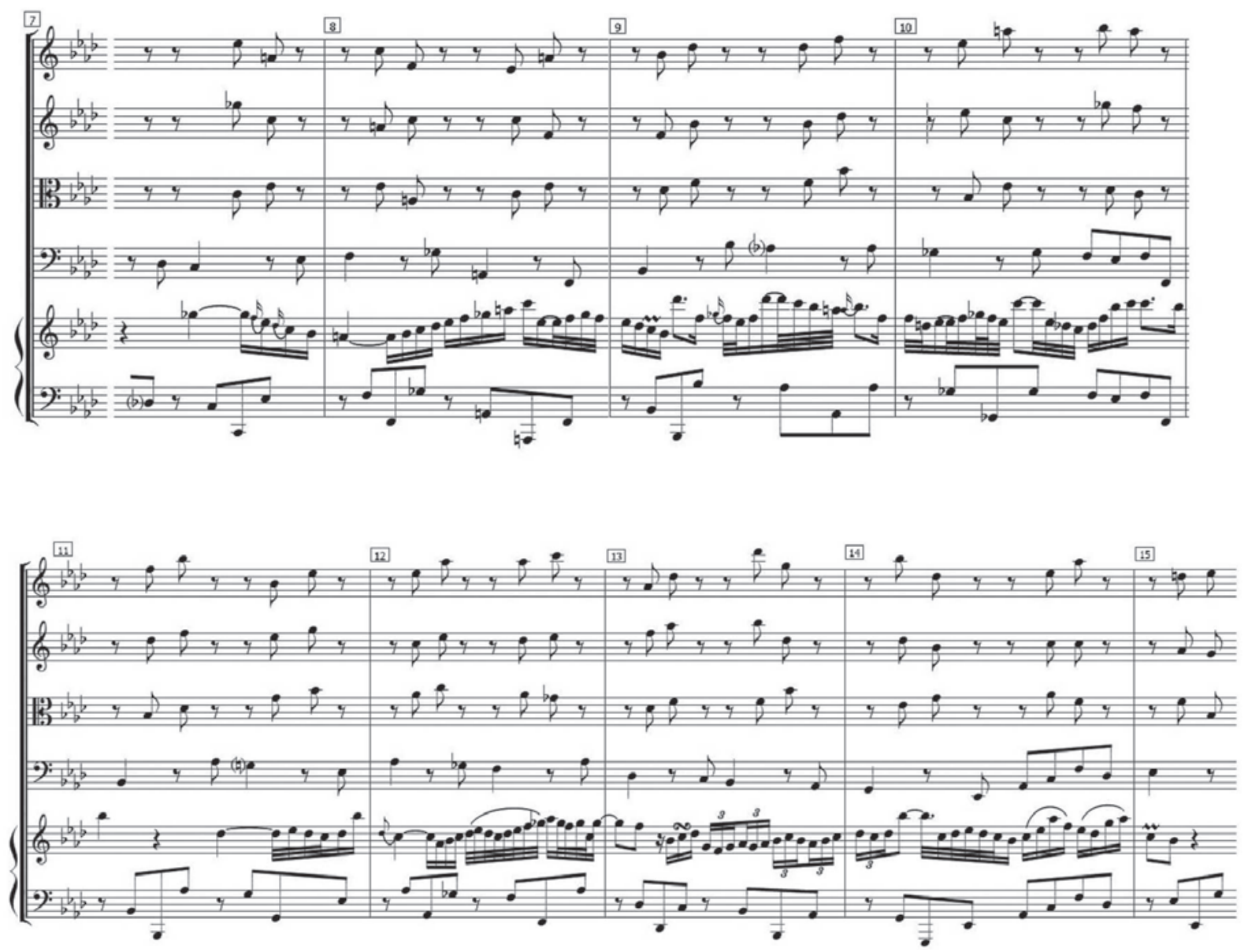

Ex.4 - Confutatio (c.7-15) no Largo do Concerto n.5 em Fá menor, BWV 1056, de J. S. Bach. 


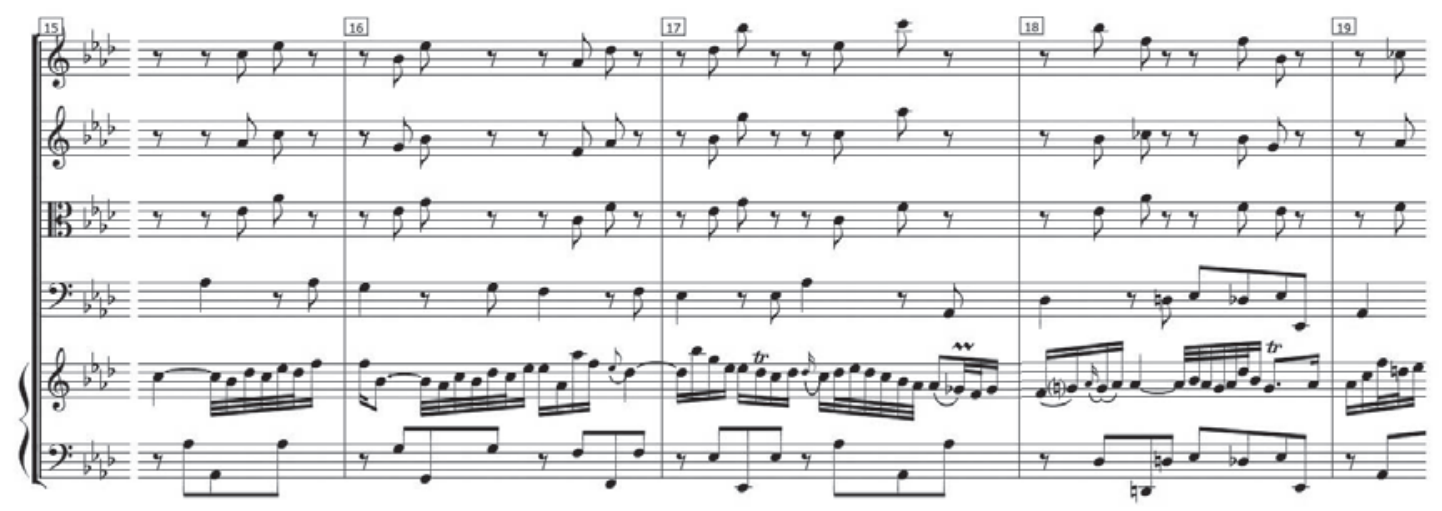

Ex.5 - Confimatio (c.15-19) no Largo do Concerto n.5 em Fá menor, BWV 1056, de J. S. Bach.

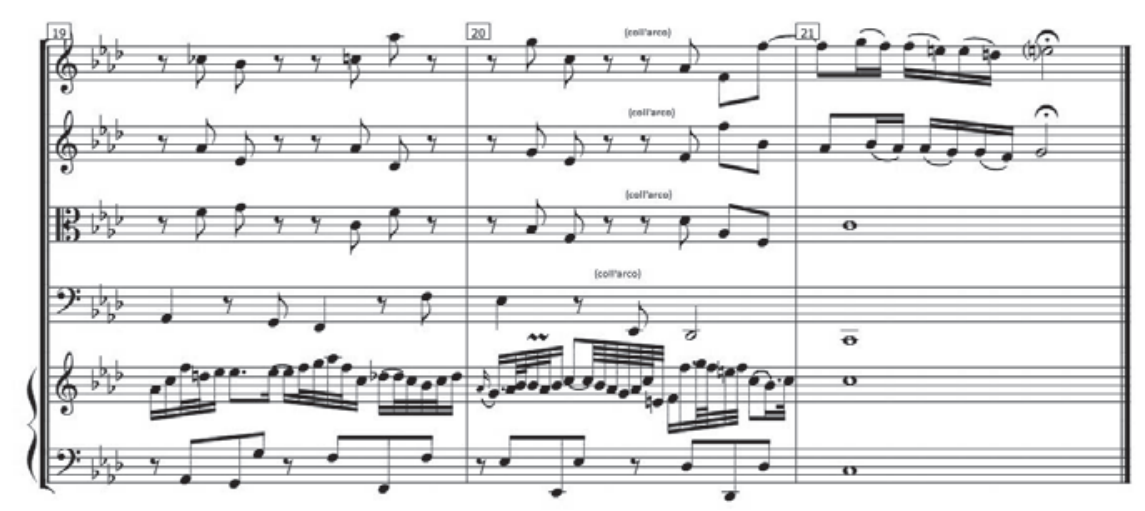

Ex.6 - Peroratio (c.19-21) do Largo do Concerto n.5 em Fá menor, BWV 1056, de J. S. Bach.

Ao domínio da Peroratio pertence a conclusão do discurso. Em música, pode ser exemplificada por uma cadência final ou pelo pedal sobre a dominante, que anuncia o término das imitações em uma fuga.

No movimento em discussão, é possível considerar os três últimos compassos como uma pequena coda, na qual a harmonia transcorre com maior movimentação (Ex.6). Os instrumentos que antes pareciam suspirar através de pizzicatos, agora se utilizam do arco para finalizar o movimento em nova textura. 0 c.21 confirma o anunciado na Peroratio: o término do Largo se dará no acorde Dó maior. Os violinos em sextas, sustentados pelos demais instrumentos através da fundamental do acorde final, concluem, em notas ligadas, a peça que até então acompanharam, contrastando com tudo o que já acontecera, um Contrast.

Os últimos compassos reservam outra aproximação entre os movimentos comentados: tanto a Sinfonia quanto o Largo são finalizados em Dó maior - para a Sinfonia, seu acorde dominante, para o Largo, acorde dominante da tonalidade do Concerto. 0 texto da ária para tenor e coro, que segue a Sinfonia, parece ilustrar esta coincidência: Nur lass mein Ende selig sein! (Só faça que meu fim seja feliz) - Dó maior para Charpentier (1670) é a atmosfera do alegre, para Quantz (1752), o intervalo de terça maior é a própria expressão da alegria. (CANO, 2000)

Discorrido acerca da organização da Dispositio, considerando as informações provenientes da Inventio e as figuras retórico-musicais pertencentes ao domínio da Elocutio, reforça-se que, para esta discussão, as particularidades da Pronuntiatio não foram comentadas. A Pronuntiatio é a execução do discurso. Gestos, movimentos corporais, entonação, modulação da voz, dicção e demais elementos da execução são abordados na Pronuntiatio. Em música, remete a conselhos práticos sobre a conduta do músico e a importância do intérprete no processo criativo musical. Em virtude de não apontar aspectos interpretativos em sua abordagem, esta análise desconsiderou as possiveis discussões acerca da Pronuntiatio do Largo do Concerto n.5, BWV 1056, de Johann Sebastian Bach, valendo-se apenas dos aspectos a ela pertinentes. 


\section{5 - Considerações finais}

Na construção deste artigo, os apontamentos retóricomusicais referidos na análise do Largo do Concerto n.5, BWV 1056, de Johann Sebastian Bach exemplificam como os princípios retóricos estão intimamente relacionados à música do período barroco. Segundo LEACH (2008, p.296), "o contexto do discurso deve ser o primeiro ponto a ser levado em consideração ao se embarcar em uma análise retórica". No exercício estabelecido, as informações pertencentes ao domínio da Inventio guiaram o olhar acerca da obra e possibilitaram aproximar o Largo do Concerto n.5, BWV 1056, à Sinfonia da Cantata Ich steh mit einem Fuß im Grabe, BWV 156. Do texto da Cantata foram extraídos eminentes significados para 0 entendimento retórico-musical do Largo, sendo este uma transcrição da Sinfonia presente no BWV 156.

A Dispositio, sobre a qual foi possivel explorar a organização do Largo, não pode ser entendida como um esquema formal e rígido, e sim como uma estrutura que emerge da própria música. As figuras retórico-musicais identificadas, mesmo desprovidas de um significado definitivo, auxiliam a compreensão da escrita musical de Bach. A força do discurso musical do compositor parece perfeitamente integrada a suas intenções expressivas que, quando o deseja, traduz na partitura uma imagem contida em um texto de forma característica.

Um dos objetivos primordiais da aplicação de princípios retóricos em música foi o de propiciar ao discurso musical a capacidade de despertar, mover e controlar os afetos da plateia. Retórica foi um instrumento de grande influência na música do período barroco. Uma investigação como a aqui proposta corrobora esta afirmação.

Uma análise retórica tem a capacidade de examinar os elementos persuasivos de um dado discurso, no entanto, em um exercício desta especificidade, as ferramentas empregadas com um corpus podem ser bastante distintas das utilizadas para outro. Conclui-se com LEACH (2008, p.308): "em síntese, a análise retórica é uma arte interpretativa".

\section{Referências}

ASSUMPÇÃO, Sérgio Eduardo Martineli de. Ascendência retórica das formas musicais. Dissertação - Mestrado em Música. Escola de Comunicação e Artes, USP: São Paulo, 2007.

BACH, Johann Sebastian. Harpsichord Concerto in F minor, BWV 1056. Mainz: Eulenburg, 1983.

BERISTÁIN, Helena. Diccionario de Retórica y Poética. Cidade do México: Porrúa, 1988.

BODKY, Erwin. The interpretation of Bach's keyboard works. Cambridge, Massig Harvar: Univ. Press, 1980.

CANO, Rubén López. Música y Retórica en el barroco. México: Universidad Nacional Autónoma de México, 2000.

LEACH, Joan. Análise Retórica. In: BAUER, Martin W.; GASKELL, George. Pesquisa qualitativa com texto, imagem e som: um manual prático. Petrópolis: Vozes, 2008. p.293-318.

MASSIN, Jean; MASSIN, Brigitte. História da música ocidental. Rio de Janeiro: Nova Fronteira, 1997.

MATTOS, Fernando Lewis de. Panorama da música no ocidente. Porto Alegre: Arena, 2009.

MERSIOVSKY, Gertrud. Organo pleno e retórica musical nos prelúdios e fugas de Johann Sebastian Bach. Rio de Janeiro: Dois Passos, 2005.

RODRIGUÊS, Ana Carolina. Análise de alguns aspectos retórico-musicais de 'Domine Deus, Agnus Dei' do Glória RV 589 de Antonio Vivaldi. IN: Música Hodie, volume 6. UFG, 2001. p.35-49.

SADIE, Stanley. Dicionário Grove de Música: edição concisa. Rio de Janeiro: Jorge Zahar, 1994.

SCHUBART, Chr. Fr. D. Ideen zu einer Ästhetik der Tonkunst, Wien, 1806. Disponível em: http://www.musebaroque.fr/ Documents/tonalites.htm. Acesso: 25 de setembro, 2011.

\section{Leitura recomendada}

BARTEL, Dietrich. Musica Poetica: musical rhetorical figures in German Baroque music. Nebraska: University of Nebraska Press, 1997. 


\section{Notas}

1 Segundo CANO (2000, p.38), o termo 'poética' (do grego crear) refere-se à teorização, normatização, sistematização, invenção de instruções, conhecimentos e recursos técnicos com os quais conta o artista durante o processo de criação. Esta nova classificação musical somou-se às categorias estabelecidas por Boécio (480-524), na Idade Média: musica theorica e musica practica.

2 De acordo com MATTOS (2009, p.37), pathos (do grego: sofrimento, paixão) é, para os antigos gregos, a utilização de figuras de retórica com a finalidade de provocar emoções intensas. Atualmente, a expressão designa os movimentos passionais (suavização ou intensificação da expressão das emoções) de uma obra de arte. Dai resulta a expressão 'patético' com o sentido de algo que revela forte emoção, que comove por ser trágico, sinistro ou, mesmo, cruel.

3 Sinfonia: termo italiano, usado a partir do Renascimento para designar vários tipos de peças (geralmente instrumentais). Em c.1700, referia-se especialmente à abertura 'italiana' em três movimentos (rápido-lento-rápido/dança).

4 Tradução livre: Since the key to understanding Bach's vocal music almost always lies in grasping the meaning of the "pictorial" elements, it is not injustifiable to search for similar devices in the keyboard music.

Pablo Alberto Lanzoni é mestrando em Comunicação e Informação da Universidade Federal do Rio Grande do Sul, onde pesquisa as aproximações entre o discurso cinematográfico e o discurso musical. Possui graduação em Música habilitação em Regência Coral (2008) pela mesma universidade. Desde 2011, é professor de música do Instituto Federal do Rio Grande do Sul - câmpus Porto Alegre. Já atuou em diferentes coros e orquestras. 